\title{
WEBSITE REVIEW
}

\section{*Prof. Sangeetha.G}

www.myygov.in is a citizen-centric platform which empowers people to connect with the Government in contributing towards good governance. This portal educates the citizens on government policies and issues like girl child education, clean ganga and Healthy India and other issues.

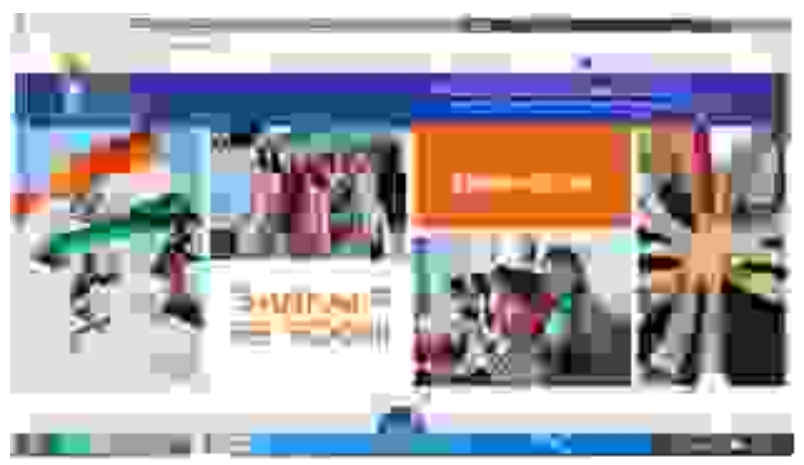

The major attributes/activities include Discussion, Tasks, Talks, Polls and Blogs on various groups based on the diverse governance and public policy issues. It has more than 1.78 million users who contribute their ideas through discussions and participate through the various earmarked tasks.

Transforming India journey - community based platform facilitates two-way communication between the Government and its people. There are many banners in this platform. A few of them are elaborated for us to understand the same. They are as follows.

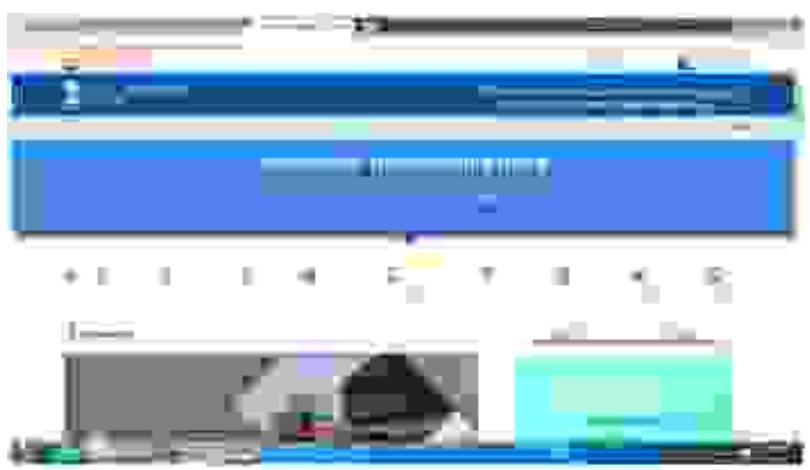

I Economic development across all sectors is among the foremost priorities of the government. This section takes you through the various policies and initiatives of the Government in this regard. Various video clippings and reports are updated weekly.

I Educational and Skills are the bases on which the edifice of an innovative and developing economy is built. You can also learn more about Skill India and how it has radically transformed the youth and job scenario in India. Live feeds in this section are uploaded by citizens.

I Farmer welfare section includes information on various policies adopted by the

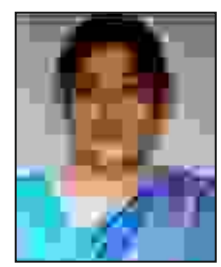

Prof. Sangeetha.G

Associate Professor

Adarsh Institute of Management

and Information Technology,

Bangalore. 
government to improve not only agricultural yield, but also to double farm income in the next five years with the ultimate objective of transforming the rural economic landscape.

I Technology is the nucleus around which the 21 st century revolves. The Government of India has taken a number of steps to foster growth in various technology sectors such as electronic goods manufacturing, software, computers and IT related products and services.

An open forum is available to share ideas or to give suggestions to the Prime Minister of India Shri. Narendra Modi.

The layout is very simple and easy to understand. Citizens without any technical background can navigate through this site.
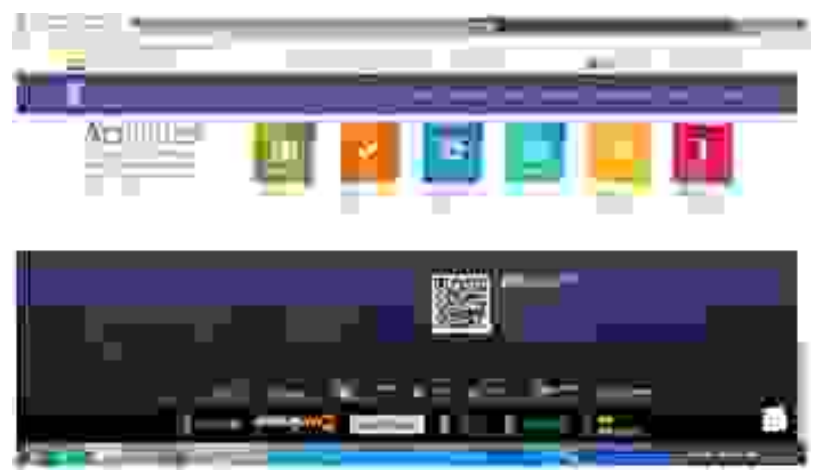

Performance dashboard is updated so that the citizens are aware about the initiatives taken and their accomplishments

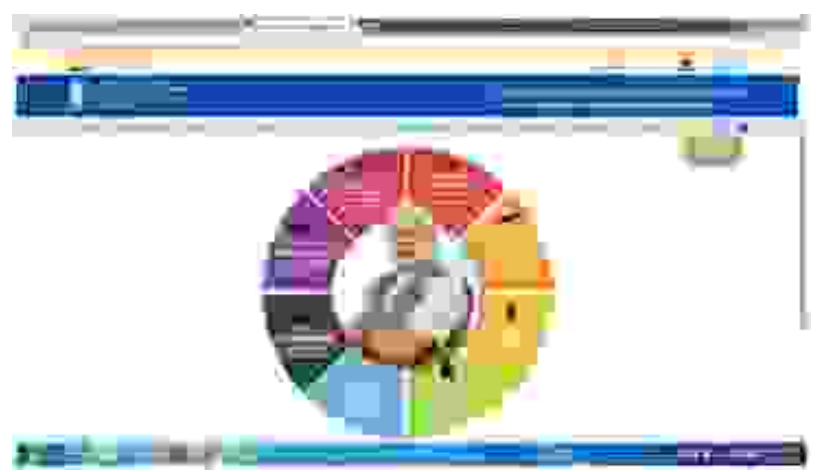

Sankalp Se Siddhi is an other platform which promotes New India Movement 2017-2022. It provides various tabs for taking pledges for building New India. The pledges include:

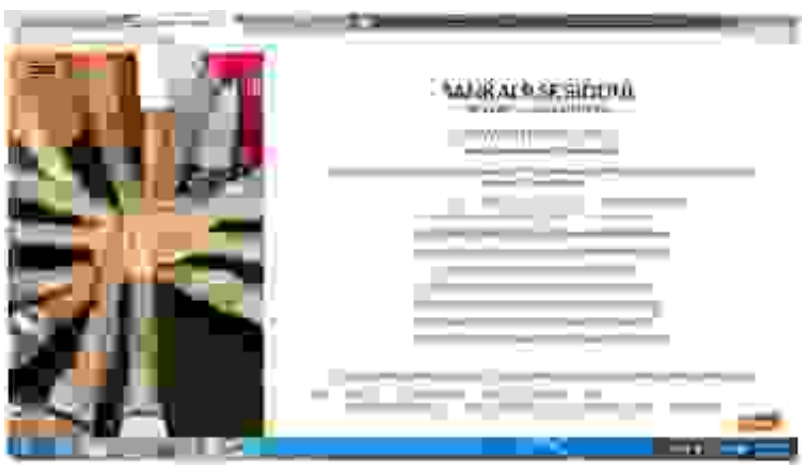

- Let us together pledge towards Corruption Free India

- Let us together pledge towards Clean India

- Let us together pledge towards Poverty Free India

- Let us together pledge towards Terrorism Free India

- Let us together pledge towards Casteism Free India

- Let us together pledge towards Communalism Free India

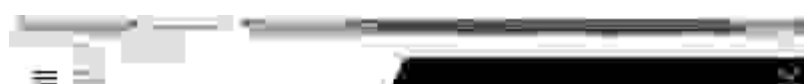
$\bar{E}=$

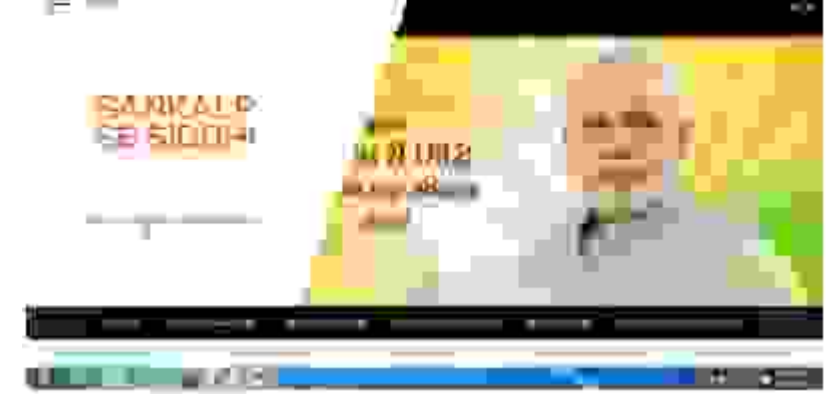


The information presented is extremely simple and navigation buttons are appropriate and all the hyperlinks function well. This portal is all set to become a key agent for important changes to usher in and accepts vital inputs from the citizens who's the ultimate beneficiary. The layout is very neat and makes the common man comfortable. I did not find any spelling mistakes. The website loads very fast with perfect navigation.

\section{Overall insights of the site}

There are certain improvements required on the following:

$\varnothing$ The home page's primary image is huge in pixel size and changes rapidly before one can read the contents. $\varnothing$ Too many videos regarding latest projects open up immediately as and when the cursor is pointed at the icons.

In summary the website is user friendly and very responsive. The server response time is very good (0.2 seconds). All the hyperlinks to social networks open to our personal pages. Banner, logo and images are very attractive. It welcomes Government Institutions to collaborate with citizens through this platform.

Henceforth this platform helps government bodies identify talent and expertise which can be garnered towards the success of projects to strengthen governance with people's participation. 